\title{
Derivation of Aero-Induced Fluctuating Pressure Environments for Ares I-X
}

\author{
Michael Y. Yang* \\ ATA Engineering, Inc., San Diego, California 92109, USA \\ John F. Wilby ${ }^{\dagger}$ \\ Wilby Associates, Calabasas, California 91302, USA
}

\begin{abstract}
A description is given of the external aero-inducted fluctuating pressure model which was fit and anchored to wind tunnel data from the past 40 years. This model is based upon the assumption that the flow around a vehicle can be divided into discrete flow zones with independent fluctuating pressure properties. The model is then used to derive fluctuating pressure environments during ascent for the Ares I-X test vehicle. A sensitivity study of the structural response to the spatial correlation of the fluctuating pressures is also performed.
\end{abstract}

\section{Nomenclature}

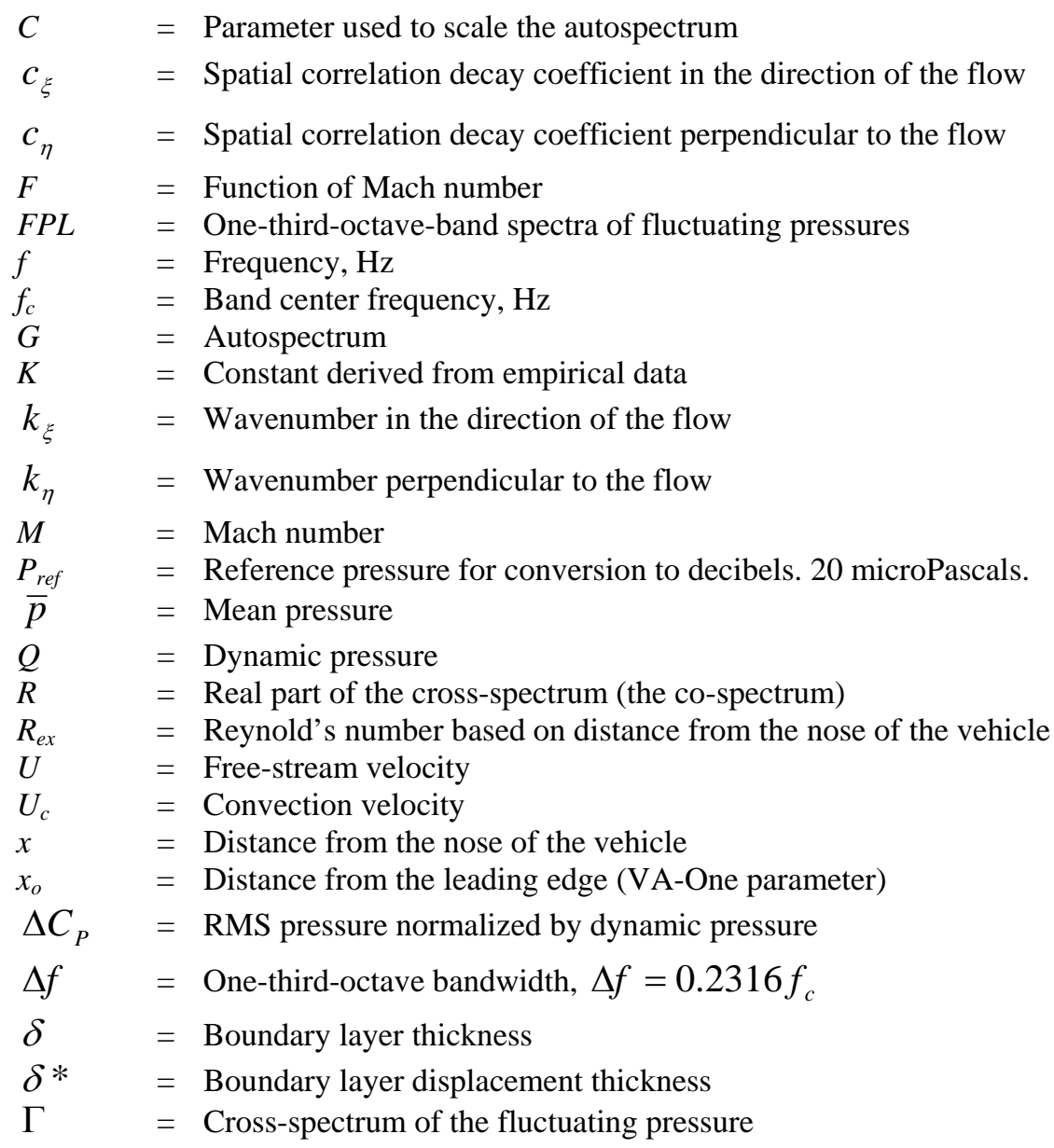

\footnotetext{
* Project Engineer, Aerospace Analysis, 11995 El Camino Real, Suite 200, AIAA Member.

${ }^{\dagger}$ Principal, 3945 Bon Homme Road, AIAA Associate Fellow.
} 


$\begin{array}{ll}v & =\text { Kinematic viscosity } \\ \xi & =\text { Distance in the direction of the flow } \\ \eta & =\text { Distance perpendicular to the flow } \\ \Omega & =\text { Strouhal number } \\ \omega & =\text { Frequency, rad/sec } \\ \sigma & =\text { Ratio of convection and free-stream velocities }\end{array}$

\section{Introduction}

WASA is responsible for the design and integration of the ARES I-X flight test vehicle for the Constellation 1 program, which will provide safer, more reliable space transportation capability for crew transport in the quest for human space exploration. The Ares I-X flight test vehicle's first flight will be a suborbital test of the booster and will test the effect of the maximum dynamic pressure being exerted on the vehicle.

Interest in the external fluctuating pressure (or aeroacoustic) environments on launch vehicles began around 1961, when a series of launch vehicle failures occurred during the transonic part of the ascent trajectory ${ }^{1}$. The turbulent flow around a launch vehicle is difficult to predict analytically, and therefore the majority of previous work $^{2-5}$ to characterize these environments has relied on empirical data measured during wind tunnel testing and flights.

This article covers the development of an external aero-induced fluctuating pressure model which was fit to generic and Saturn/Apollo configuration wind tunnel data, and also anchored to Atlas and Titan flight data. This model was then used to predict the aeroacoustic environment for the Ares I-X vehicle during ascent. A sensitivity study of the structural response to the spatial correlation of the fluctuating pressures is also performed

\section{Flow Regimes for Ares I-X}

The air flow around any vehicle traveling through the atmosphere can be divided into separate flow regimes. These flow regimes are dependent upon the geometry of the vehicle as well as the flight conditions. This section describes the Ares I-X as well as the flow regimes that occur around the vehicle.

\section{A. Description of Ares I-X}

The Ares I-X test vehicle consists of a Crew Launch Vehicle (CLV) with an active first stage and a Crew Exploration Vehicle (CEV) simulator integrated into a single vehicle for launch. The CEV is comprised of the Launch Abort System (LAS), the Crew Module (CM), the Service Module (SM), and the Spacecraft Adapter (SA). The three major structural sub-assemblies are the First Stage (FS), the Upper Stage Simulator (USS) element, and the CEV Simulator. A stack view is shown in Figure 1. 


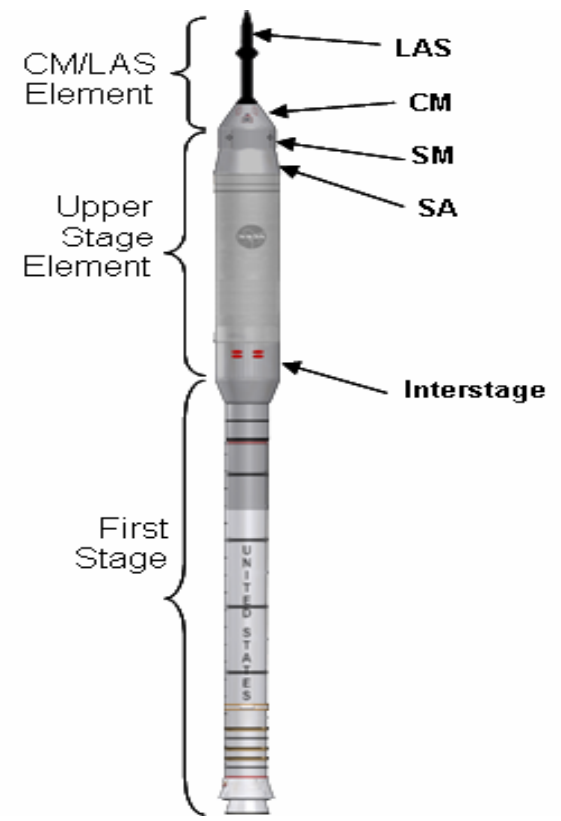

Figure 1. Ares I-X Vehicle

\section{B. Attached Turbulent Boundary Layer}

The fluctuating pressures caused by an attached turbulent boundary layer (TBL) are substantially lower than those associated with separated flow. As a result, attached flow regimes are not likely to affect the vehicle design significantly. These types of flow typically occur in regions that exhibit relatively smooth surfaces that are sufficiently far from any changes in vehicle geometry such as corners, changes in vehicle diameter, and protuberances. Figure 2 shows the attached turbulent boundary regions for Ares I-X. Attached TBL regimes occur on the LAS Tower and over the majority of the USS and FS.

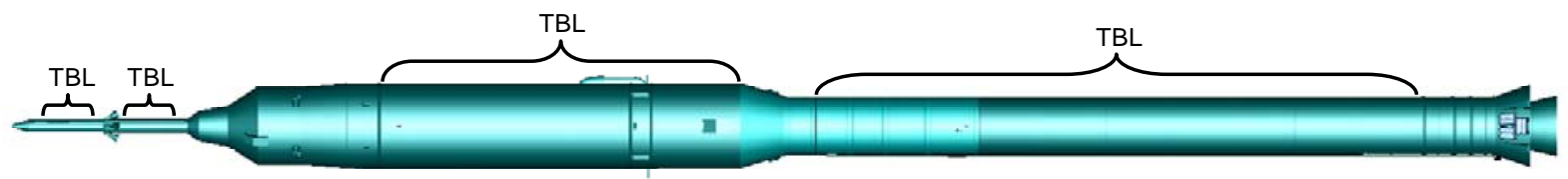

Figure 2. Attached TBL Regions for Ares I-X

\section{Compression Corners}

Flow at a compression corner, such as the junction between a cylinder and a conical frustum, causes separation of the boundary layer. Shockwaves form at the flow separation and reattachment points during supersonic flight (see Figure 3). During transonic flight, shockwaves may not form but there will still be high fluctuating pressures at the flow reattachment point. Figure 4 shows that the peak RMS pressure occurs at the flow separation and reattachment locations, with a "plateau" region of lower fluctuating pressures existing between these two locations. 


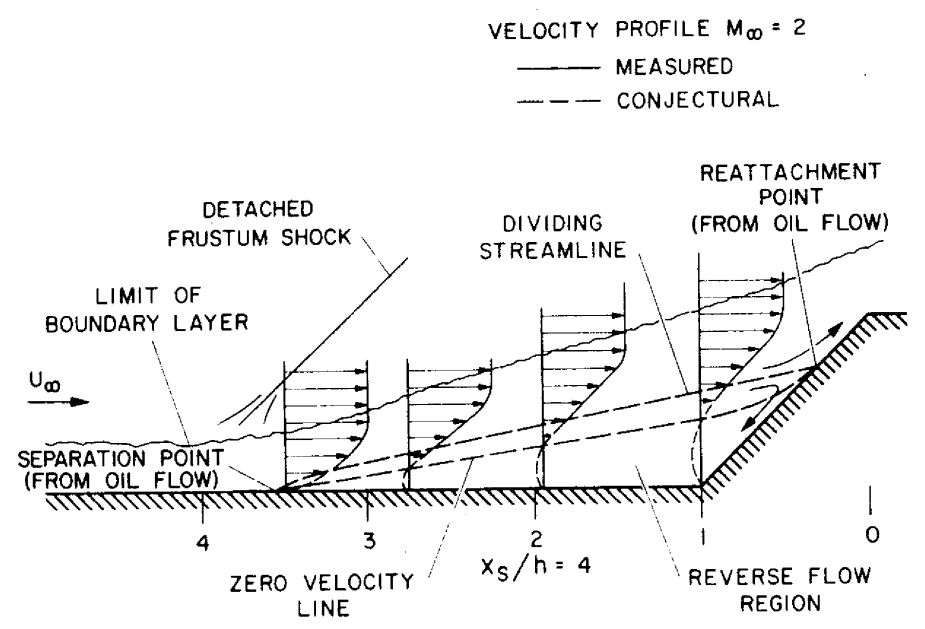

Figure 3. Representation of flow at a compression corner for supersonic flow ${ }^{7}$

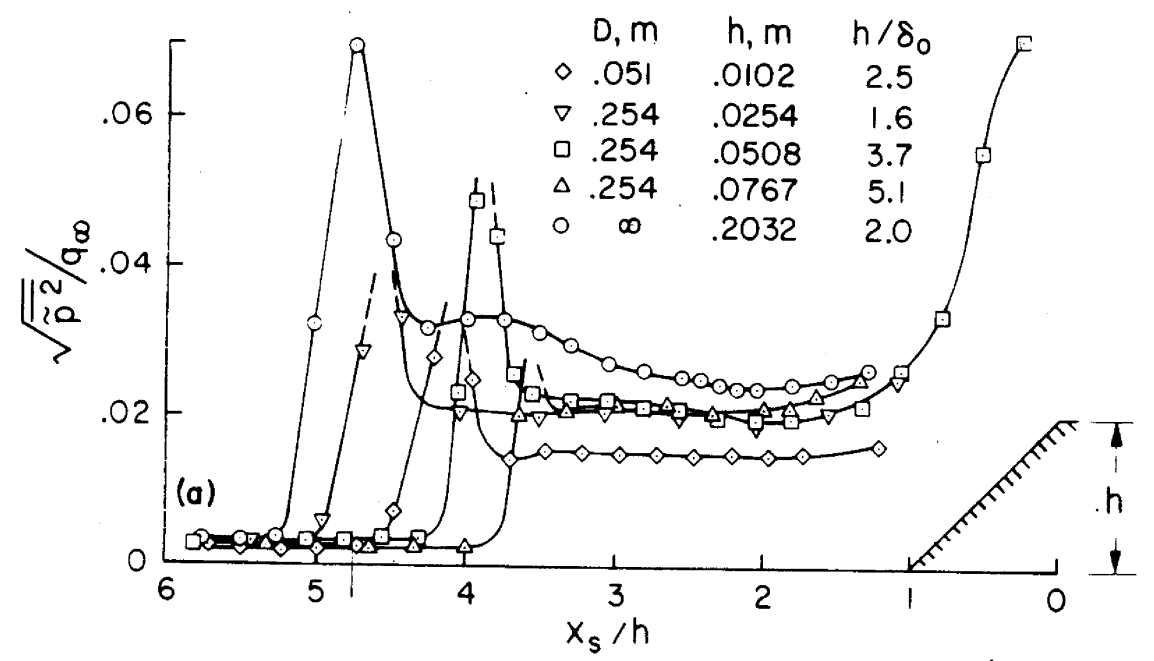

Figure 4. Fluctuating pressures at a compression corner ${ }^{4}$

Examination of data from Apollo/Saturn wind tunnel tests ${ }^{7,8}$ shows that the RMS pressures can increase significantly at a compression corner which is downstream of a protuberance. For Ares I-X, this occurs at the Crew Module, which is downstream of the protruding Launch Abort System abort motor nozzles (see Figure 5). 


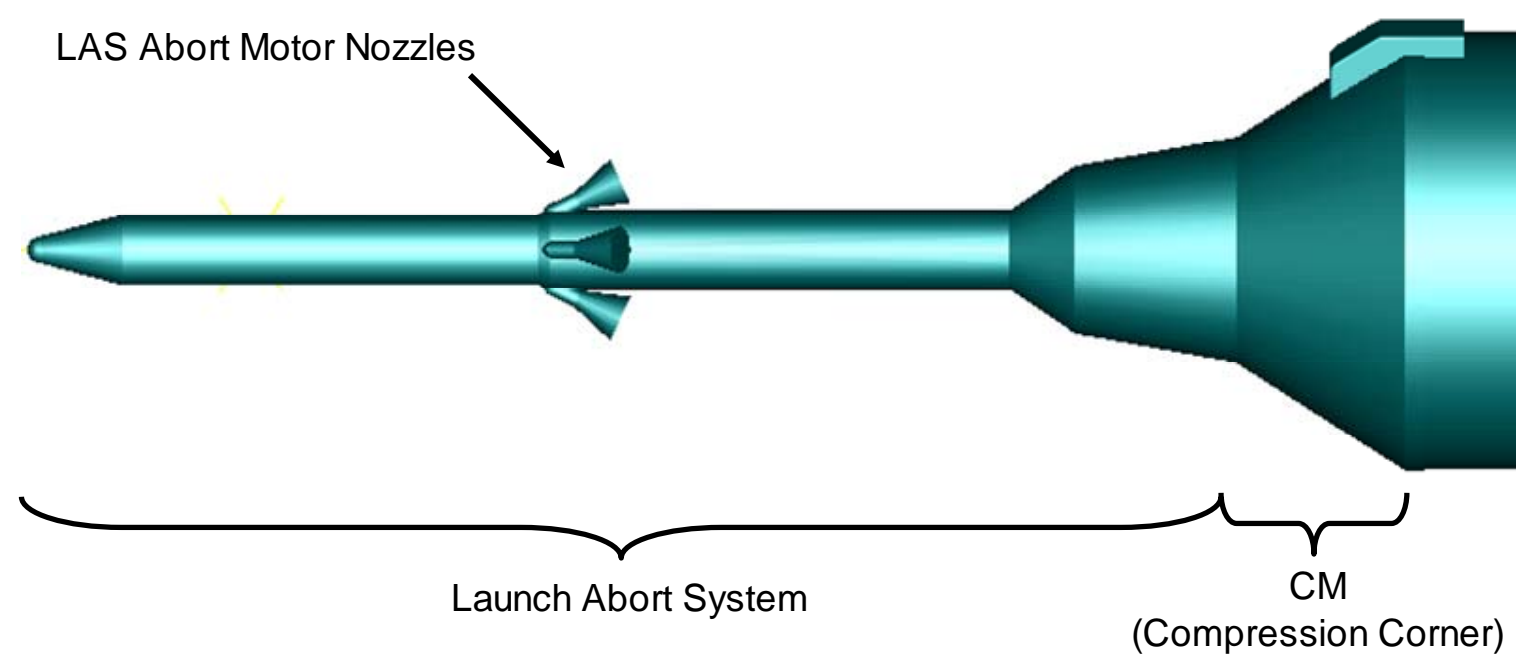

Figure 5. Compression corner occurs at CM. Fluctuating pressures are increased significantly by upstream protruding LAS Abort Motor Nozzles

\section{Expansion Corners}

Expansion corners occur at the shoulder of a cone-cylinder junction or at boattails. Flow over an expansion corner accelerates, forms an expansion fan, and can be supersonic even under nominally transonic conditions. The flow then must quickly decelerate to the free-stream velocity of the fluid. This deceleration can result in an attachment shock, which causes very high fluctuating pressures at the point of attachment. Fluctuating pressures near an expansion corner are typically highest in the transonic Mach range $(0.7<\mathrm{M}<1.0)$ since the flow is fast enough to achieve supersonic speeds around the corner while still needing to undergo significant deceleration. Fluctuating pressures at higher and lower Mach numbers tend to be lower because less deceleration is required and because the flow may never achieve supersonic speeds around the corner at the lower Mach numbers.

The fluctuating pressures at an expansion corner are characterized by a region of high fluctuating pressures occurring within one vehicle diameter downstream of the corner, followed by a region of lower fluctuating pressures which occur over one more vehicle diameter downstream of the corner. These are known as the "peak" and "plateau" regions of the expansion corner, respectively and are illustrated in Figure 6 for Ares I-X. The area over which these regimes occur is approximate, and varies with vehicle geometry and flight conditions. Wind tunnel tests and computational fluid dynamic (CFD) analyses are required to define the region more accurately.

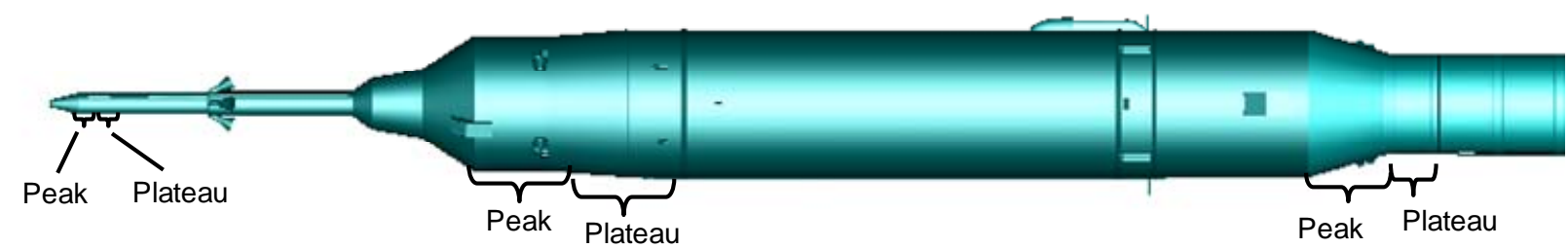

Figure 6. Expansion corner regimes for Ares I-X. Peak pressures occur within one vehicle diameter of the corner, and plateau pressures occur within one additional vehicle diameter.

\section{Change in Flow Behavior at the Frustum}

CFD analysis performed by Craig L. Streett (NASA Langley Research Center) shows that a significant change in flow behavior occurs from Mach 0.95 to Mach 1.05. Figure 7 shows that at Mach 0.95, the flow separates at the forward end of the Frustum and causes a strong transonic shock. However, at Mach 1.05, the flow stays attached to the corner at the forward end of the Frustum. As a result, the authors have made the assumption that the flow at the Frustum changes as shown in Figure 8. 


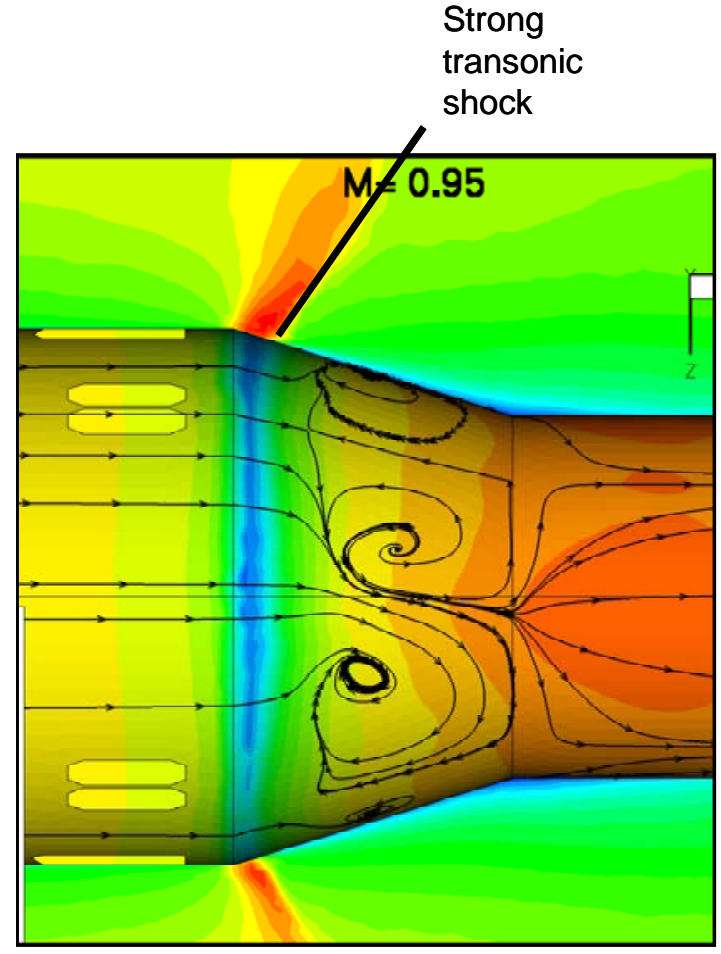

(a) Flow separates and strong transonic shock occurs at Mach 0.95

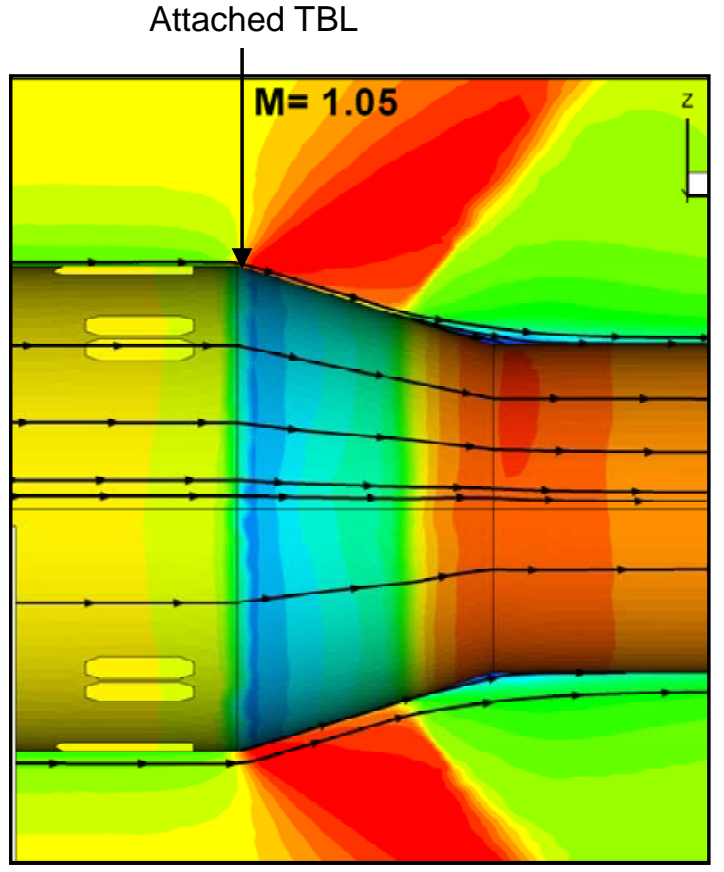

(b) Flow remains attached at Mach 1.05

Figure 7. CFD analysis shows a significant change in flow behavior at the Frustum from Mach 0.95 to 1.05. Contours in fluid shows Mach number, contours on surface show static pressure.

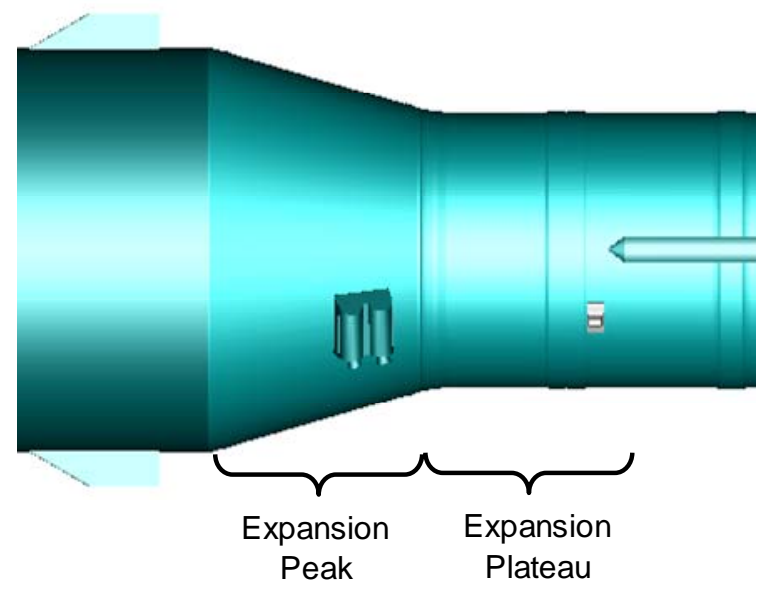

(a) Assumed flow regime below Mach 1.0

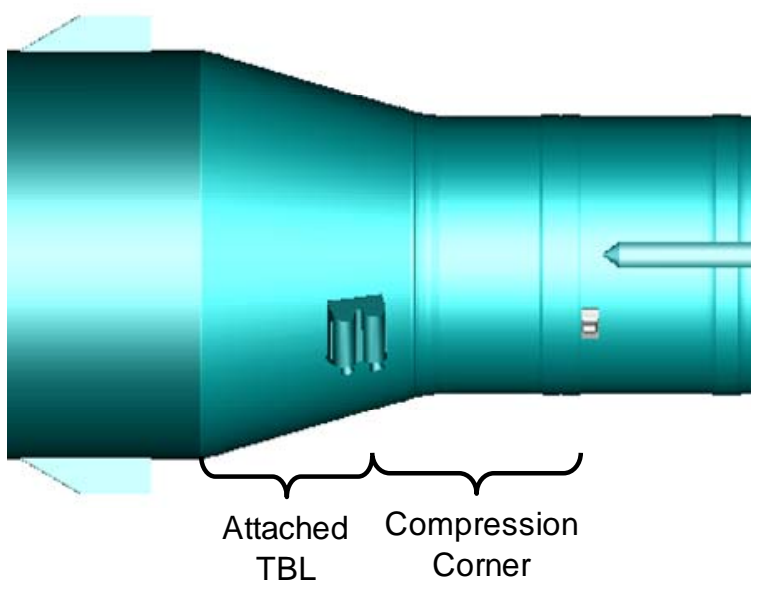

(b) Assumed flow regimes above Mach 1.0

Figure 8. Change in assumed flow regimes as a result of change in flow behavior at the Frustum

\section{E. Protuberances}

There are over twenty protuberances on Ares I-X that require the local fluctuating pressure environment to be defined. These protuberances are distributed over the entire length of the vehicle (Figure 9) and have significantly different geometries. It is not possible to compute the fluctuating pressure level (FPL) for each of these 
protuberances without a detailed Ares I-X wind tunnel test, and therefore the protuberance FPL model used here was derived from wind tunnel data published in the literature. As a result, the protuberance FPL model is necessarily rather coarse and does not account for all of the geometric details for each protuberance.

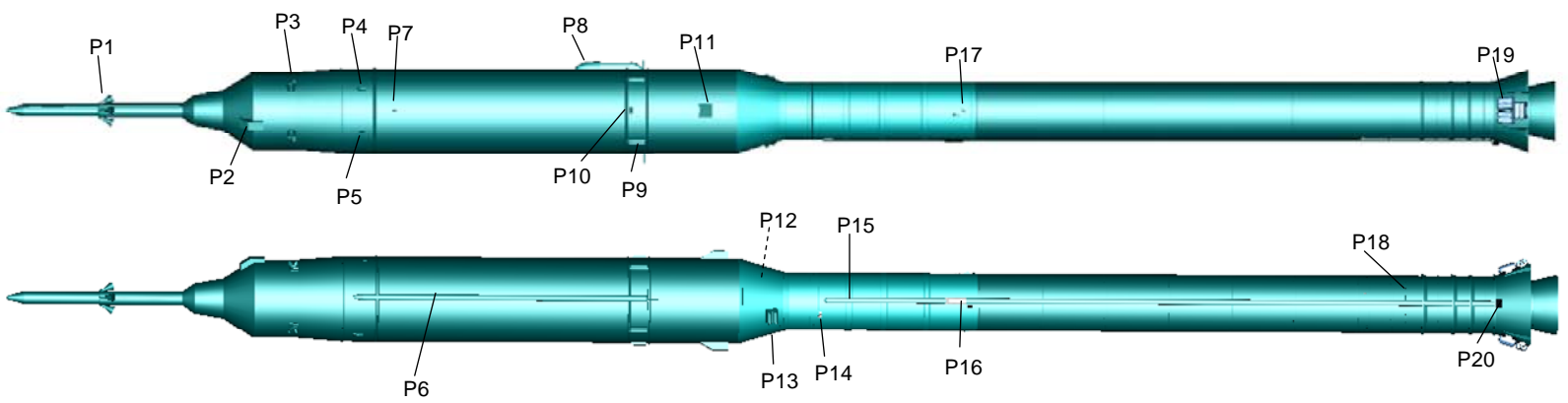

Figure 9. Protuberances for Ares I-X. Protuberances of note include the LAS Abort Nozzles (P1) and the Roll Control System (P11).

General characteristics of the fluctuating pressure fields near two-dimensional steps and three-dimensional protuberance have been discussed by Speaker and Ailman ${ }^{9}$ and Robertson ${ }^{2}$, respectively. Their proposed flow conditions and measured pressure distributions are shown in Figure 10 and Figure 11. These figures show that the FPL varies in the vicinity of the protuberance, but the protuberance model is designed to capture only the peak fluctuating pressure.

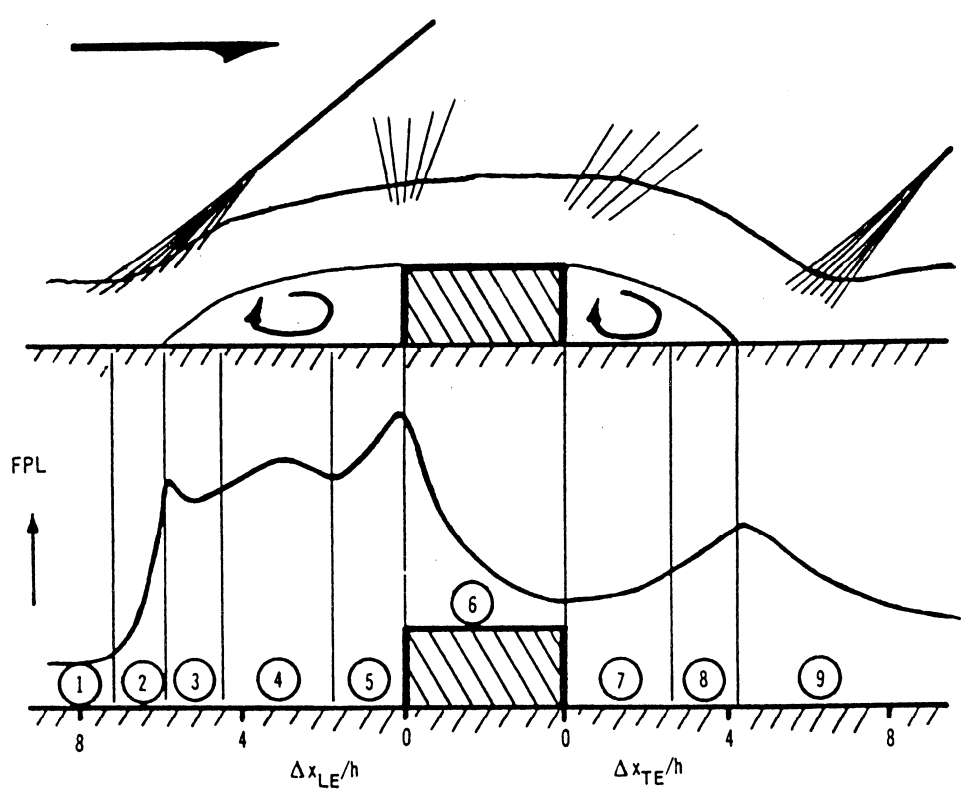

Figure 10. Flow and FPL for a two-dimensional step ${ }^{9}$ 


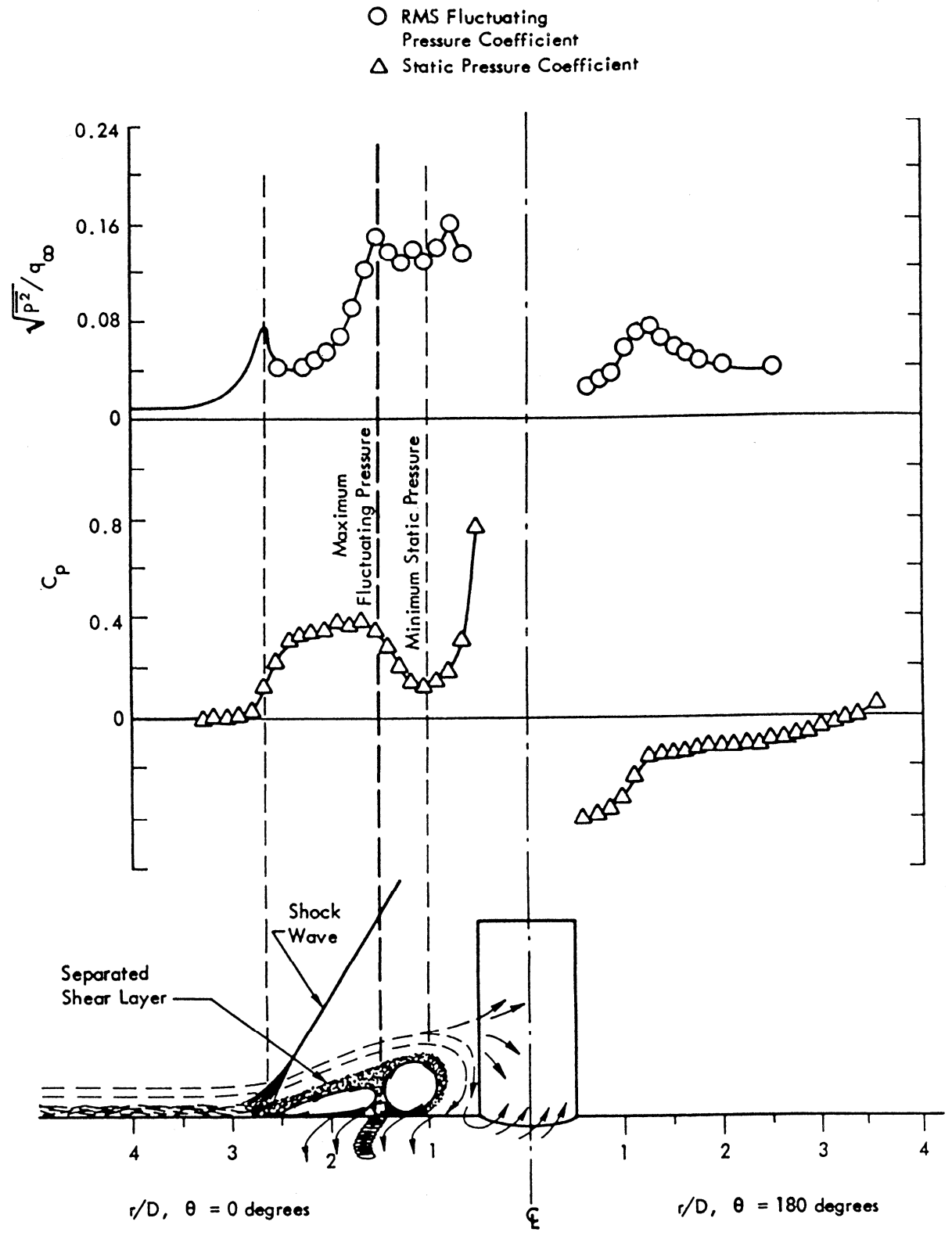

Figure 11. Flow and FPL for three-dimensional protuberance ${ }^{2}$

The height of the protuberance has been identified as a critical factor. George ${ }^{11}$ found that the height of the protuberance must be at least half the boundary layer thickness in order for the flow to separate. Once the flow separates, an oblique shock wave is generated which causes significantly higher FPL.

The boundary layer thickness for Ares I-X was calculated using Equation 1 for Ares I-X at Mach 0.9 (transonic) and Mach 1.9 (maximum dynamic pressure). This equation assumes that the boundary layer grows steadily over the length of the vehicle, regardless of any flow separation.

$$
\delta=\frac{0.0371\left(10.286+0.693 M^{2}\right) x}{R_{e x}^{0.2}\left(1+0.13 M^{2}\right)^{0.64}}
$$

where the Reynold's number is based on the distance from the nose of the vehicle. 


$$
R_{e x}=\frac{U x}{v}
$$

Figure 12 shows that the majority of protuberances have a height that is larger than half the boundary layer thickness (BLT). This indicates that the protuberance model should be reasonably accurate for the majority of the protuberances on Ares I-X. There are several protuberances on the First Stage with insufficient height but it was determined that the model would be used to derive FPL environments for these protuberances with the understanding that the results would likely be conservative.

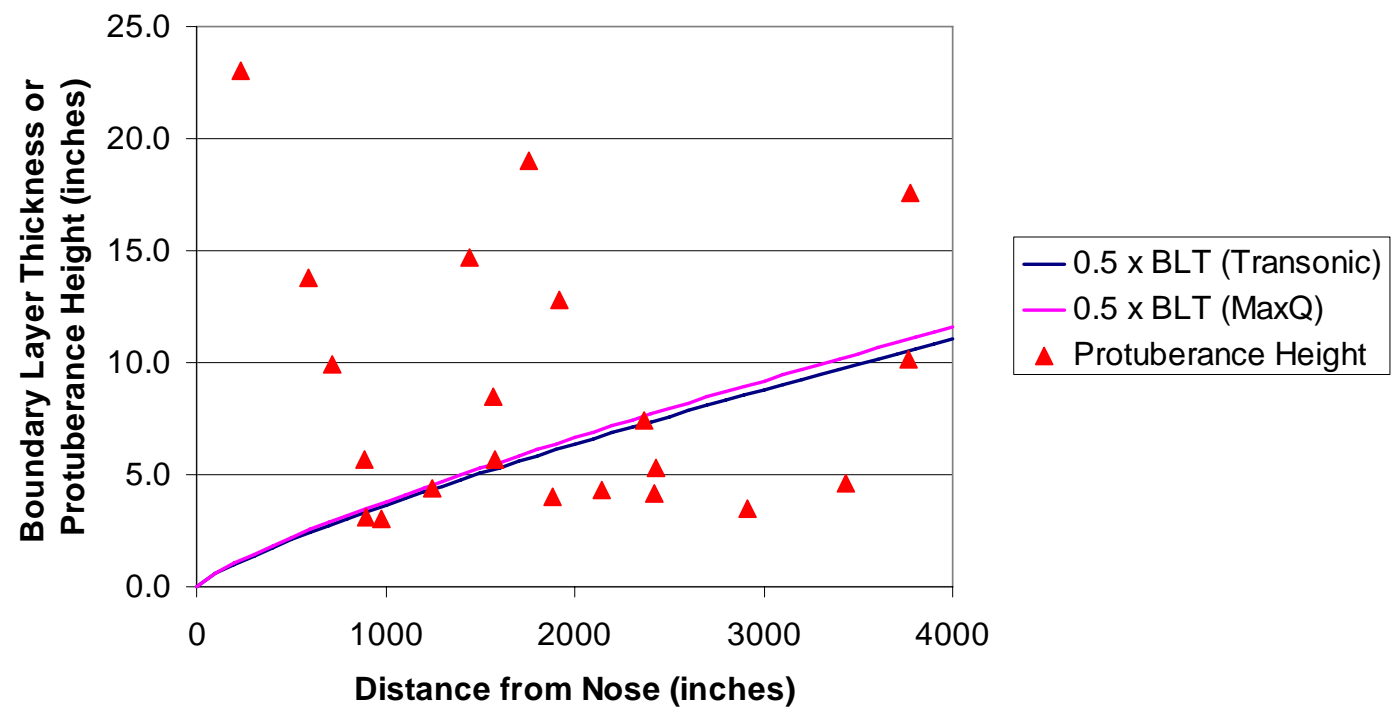

\section{Figure 12. The majority of protuberances on Ares I-X are taller than half the boundary layer thickness. CM/SM junction occurs at 588 inches, $2^{\text {nd }}$ Stage/Frustum junction occurs at 1800 inches, Frustum/ $1^{\text {st }}$ Stage junction occurs at 2000 inches}

The fluctuating pressure level has also been found to depend on the slope of the protuberance relative to the flow. A sharp fin inclined at an angle to the flow generates relatively weak fluctuating pressures compared to a blunt fin, which generates much higher fluctuating pressures ${ }^{12,13}$. Reducing the angle of a conical protuberance from 17 degrees to 10 degrees reduced the FPL by about $6 \mathrm{~dB}^{14}$. A cylinder normal to the boundary layer represents a particularly severe condition ${ }^{2}$. As a result, the angle of the protuberance relative to the boundary layer is taken into account for the protuberance FPL model. This angle only has an effect on predictions for supersonic flow, as there is insufficient wind tunnel data for protuberances of differing angles in transonic flow.

\section{Aeroacoustics Fluctuating Pressures Model}

The model for fluctuating pressures is based upon wind tunnel data collected and published over the past 40 years and envelopes the majority of the measured fluctuating pressures in each flow regime. As a result it is purposefully conservative. This is partially to account for the fact that the model does not account for flow changes due to non-zero angle of attack of Ares I-X. It is assumed that the flow around the vehicle can be sub-divided into discrete aerodynamic flow regions, with each region having independent flow behavior. The resulting fluctuating pressure in each zone is defined by its own root-mean square (RMS) pressure, autospectrum, and cross-spectrum.

\section{RMS Pressure}

The root-mean-square (RMS) pressure is proportional to the dynamic pressure, $Q$, and typically has the form: 


$$
\sqrt{\bar{p}^{2}}=\frac{K}{F} Q=\Delta C_{P} Q
$$

Where $K$ is a constant determined from empirical data and $F$ is a function of Mach ${ }^{\ddagger} . \Delta C_{P}$ is referred to as the fluctuating pressure coefficient.

\section{Autospectrum}

It was assumed that the autospectrum has the same form for all of the flow regimes, shown in Equation 4.

$$
\begin{gathered}
G(f)=\frac{4 C \delta^{*} F^{1.433}}{U\left(1+C^{2} F^{2.867} \Omega^{2}\right)} \bar{p}^{2} \\
\Omega=\frac{2 \pi f \delta^{*}}{U}
\end{gathered}
$$

The autospectrum given by Equation 4 is a smoothly varying function of frequency and can be converted into one-third-octave-band fluctuating pressure levels using Equation 6.

$$
F P L\left(f_{c}\right)=10 \log \left(\frac{G\left(f_{c}\right) \Delta f}{P_{r e f}^{2}}\right) \mathrm{dB}
$$

Examples of one-third-octave-band spectra calculated using Equation 6 is plotted in Figure 13, which shows that the spectrum slope is $+10 \mathrm{~dB} /$ decade at low frequencies and $-10 \mathrm{~dB} /$ decade at high frequencies. The parameter $C$ is used to adjust the frequency at which the spectrum levels are a maximum. Higher values of $C$ result in a greater amount of low-frequency content ${ }^{\S}$. In general, flow regimes which are influenced by shocks exhibit higher levels in the low frequency bands. Therefore, $C$ is larger for peak pressures, and smaller for attached flow.

The spectrum also shifts to lower frequencies as the boundary layer displacement thickness increases. The result is that the aeroacoustic environments at the aft end of the vehicle typically have slightly more low-frequency content compared to the forward end. However, the presence of shocks has a greater influence on the spectrum than the boundary layer displacement thickness.

\footnotetext{
${ }^{\ddagger}$ ITAR restrictions prevent the authors from explicitly stating the values of $K$ and $F$.
}

${ }^{\S}$ ITAR restrictions prevent the authors from explicitly stating the values of $C$. 


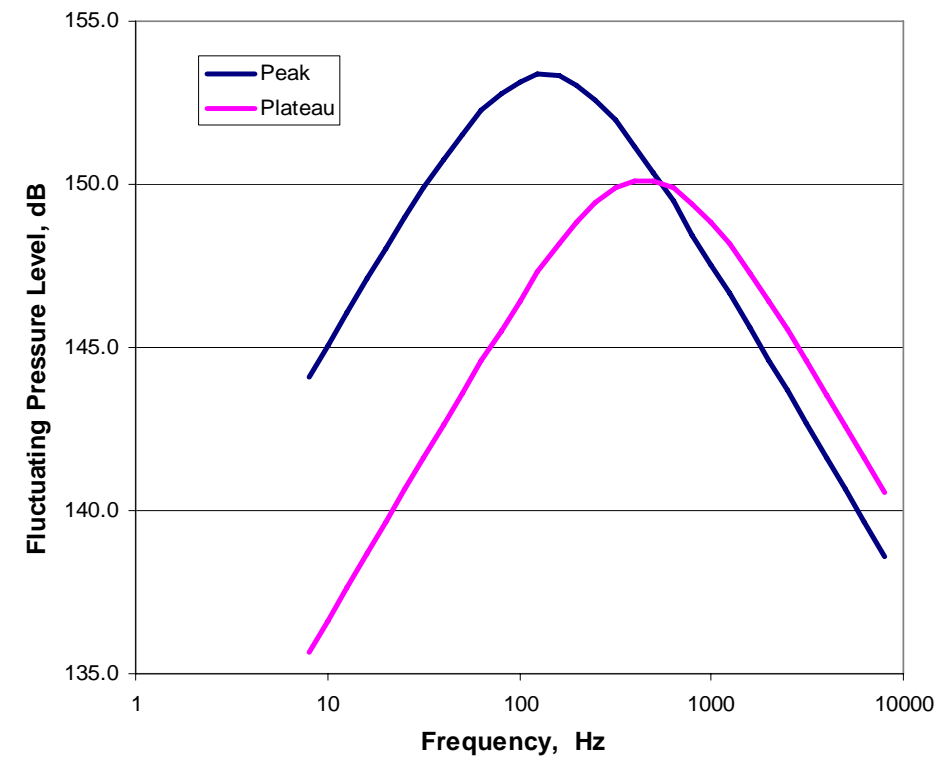

Figure 13. Peak and plateau spectrum at a compression corner. Higher values of fluctuating pressure shift the spectrum lower in frequency.

\section{Cross-spectrum}

Prediction of the pressure cross-spectrum is particularly difficult since the results in the literature are often inconsistent and since the spatial distribution of the pressure varies rapidly, particularly in regions of separated flow. This is unfortunate because the predicted structural responses are very sensitive to the cross-spectral values.

$\operatorname{Corcos}^{15}$ suggested the following general form for the cross-spectrum, where all parameters can be frequencydependent.

$$
\Gamma(\omega, \xi, \eta)=G(\omega) A(\alpha) B(\beta) e^{-i k_{\xi} \xi}
$$

Corcos further suggested that the cross-spectrum is separable in the longitudinal (in flow) and tangential (crossflow) directions. The longitudinal and tangential portions are expressed in Equation 8 and Equation 9, respectively.

$$
\begin{gathered}
\Gamma(\omega, \xi, 0)=G(\omega) A(\alpha) e^{-i k_{\xi} \xi} \\
\Gamma(\omega, 0, \eta)=G(\omega) B(\beta)
\end{gathered}
$$

The function of primary interest is the co-spectrum, which is the real part of the cross-spectrum. This reduces Equation 8 and 9 to:

$$
R(\omega, \xi, \eta)=G(\omega) A(\alpha) B(\beta) \cos \left(k_{\xi} \xi\right)
$$

Measurements by several investigators ${ }^{16}$ show that the co-spectrum of a turbulent boundary layer pressure fluctuation in the direction of the flow can be approximated by an exponentially damped cosine function, and the cospectrum across the flow can be approximated by a decaying exponential function. Combining this observation with Equations 10 yields Equation 11, which is illustrated in Figure 14.

$$
R(\omega, \xi, \eta)=G(\omega) e^{-\alpha(\omega, \xi)} e^{-\beta(\omega, \eta)} \cos \left(k_{\xi} \xi\right)
$$




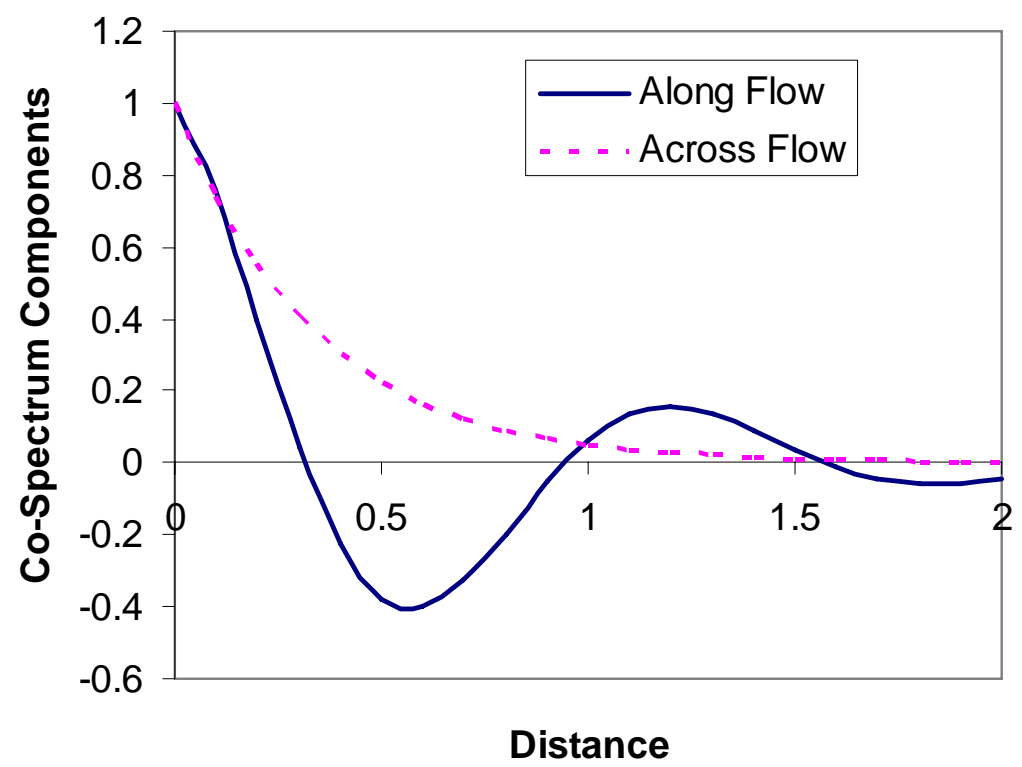

Figure 14. Cross-correlation coefficients as a function of distance.

The wavenumber, $k_{\xi}$, is the angular frequency $\omega$ divided by the convection velocity ${ }^{* *}, U_{c}$, and is a critical parameter for determining the structural response to turbulent boundary excitation. Unfortunately, there is a considerable discrepancy among the different estimates for the convection velocity, which is often a function of frequency ${ }^{17}$. This is illustrated in Figure 15, which compares the convection velocities as a function of frequency as reported by different researchers. The Bies ${ }^{10}$ and Lowson ${ }^{16}$ models refer to attached boundary layers whereas Cockburn and Robertson ${ }^{5}$ (C\&R) refer to separated flow.

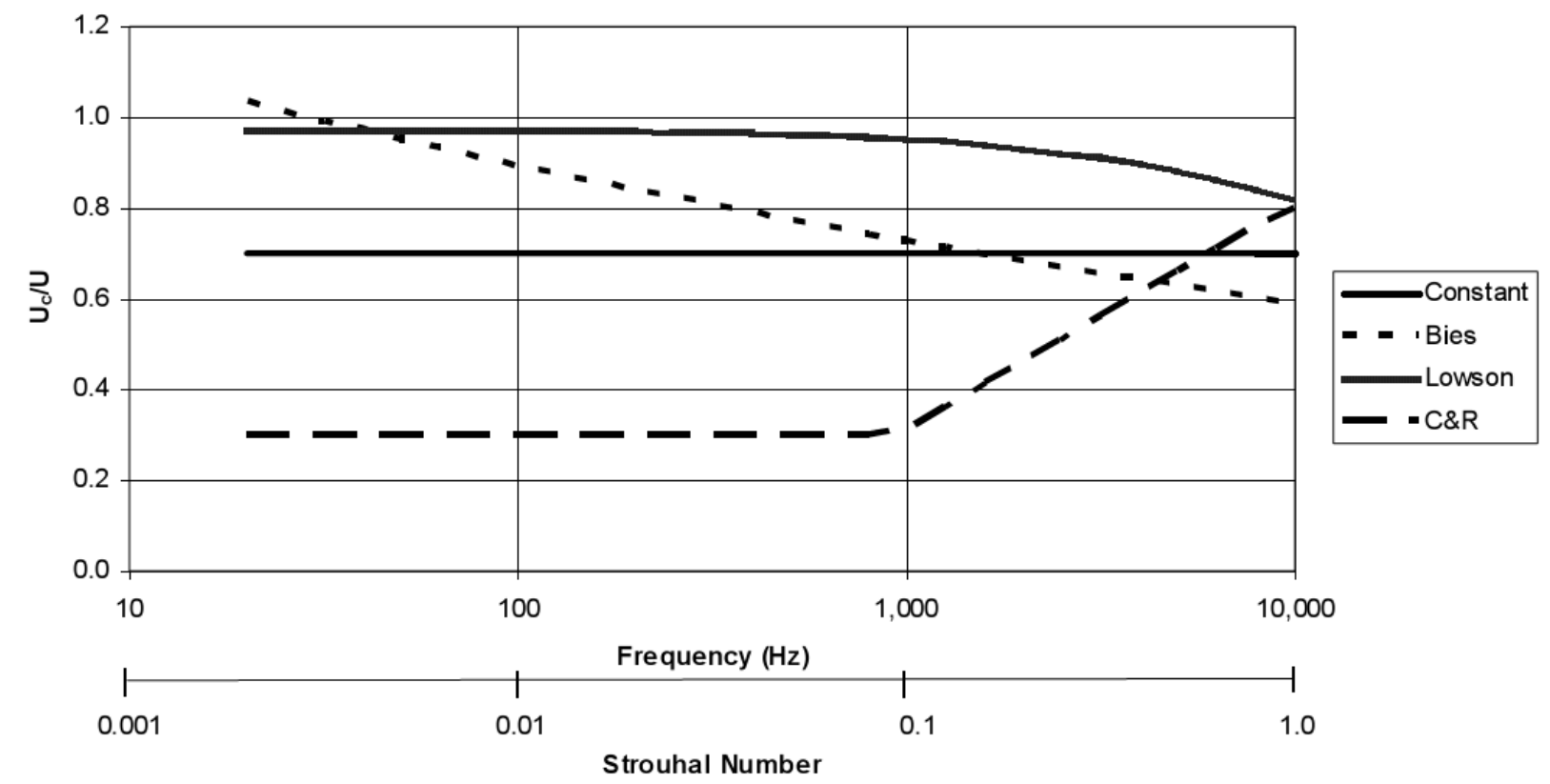

Figure 15. Convection velocity vs. frequency for a typical launch vehicle application ${ }^{17}$

\footnotetext{
** The convection velocity is the velocity at which the fluctuating pressure field propagates beneath a turbulent boundary layer. It is usually expressed as a fraction of the free-stream velocity.
} 


\section{Fluctuating Pressure Results for Ares I-X}

This section presents selected fluctuating pressure predictions for Ares I-X. They include RMS pressures for the ascent trajectory as well as FPL spectra at selected locations of interest. Complete results are not given for sake of brevity.

Figure 16 shows the RMS pressure levels at several regions of interest (illustrated in Figure 17) on Ares I-X during the ascent trajectory. Areas in a compression regime such as the CM have the highest RMS pressures of overall fluctuating pressure levels (OAFPL) during the maximum dynamic pressure (MaxQ) phase of ascent, whereas areas in an expansion regime such as the SM have the highest OAFPL during transonic. The OAFPL for the Forward and Aft Frustum show a discontinuity near Mach 1.0 because this is the Mach number at which the flow is assumed to change from a separated to an attached boundary layer (see Figure 7). Attached TBL pressures are significantly lower than other flow regimes.
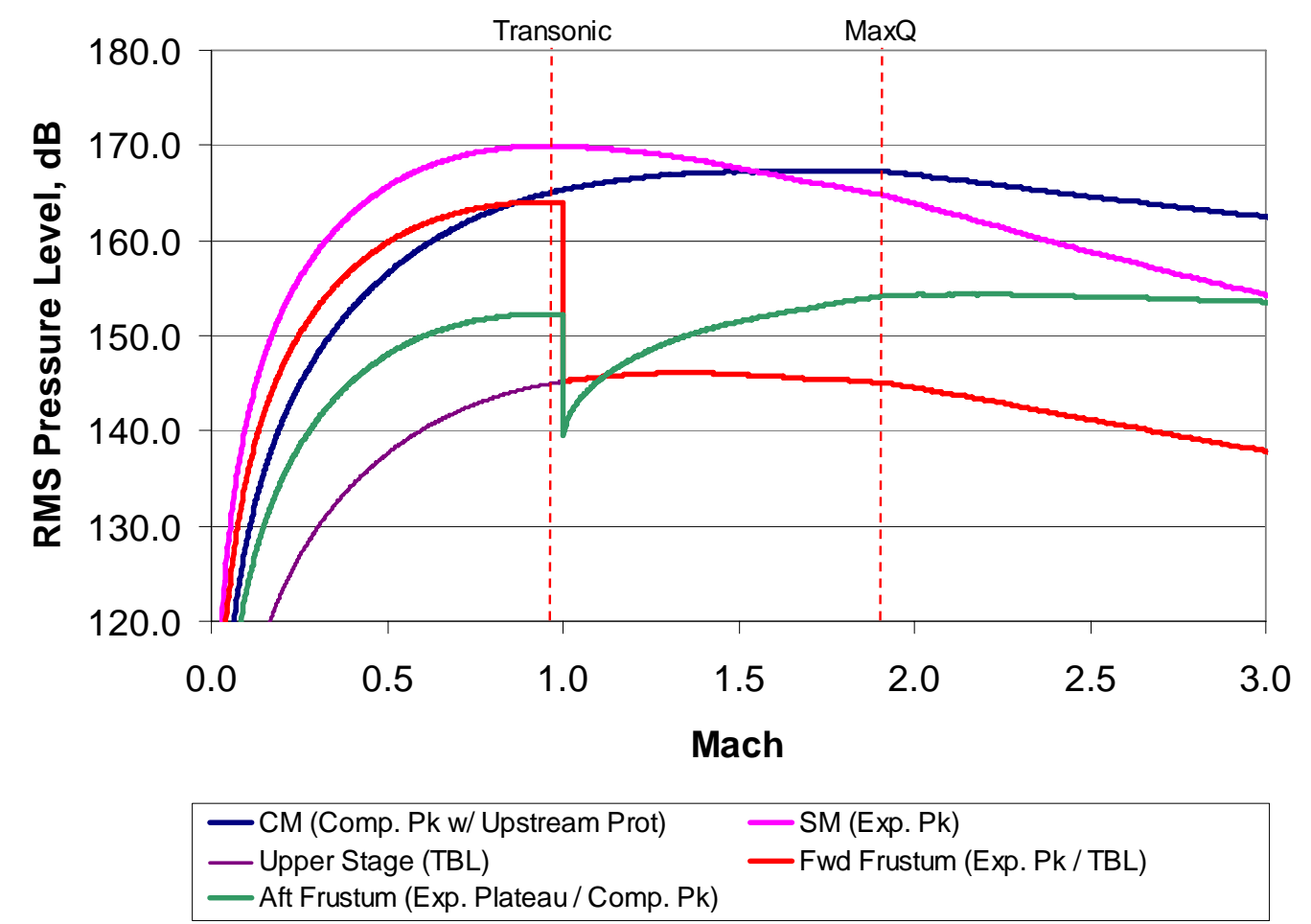

Figure 16. OAFPL at different regions on Ares I-X during ascent. Reference $=20$ microPascals

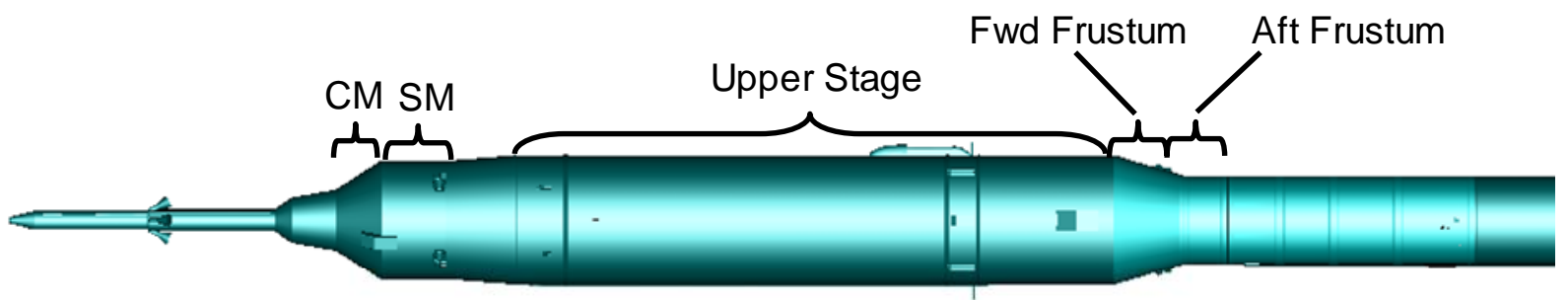

Figure 17. Areas of interest on Ares I-X

Figure 18 shows the RMS pressure levels for some of the protuberances on Ares I-X during ascent (see Figure 9 for illustration of protuberances). The predicted OAFPL below Mach 1.6 is the same for all protuberances because 1) the protuberances were all assumed to have sufficient height to cause boundary layer separation, and 2) there was 
insufficient wind tunnel data to evaluate the effect of protuberance angles in this Mach range. The OAFPL above Mach 1.6 is highest for those protuberances which are at normal angles to the boundary layer.

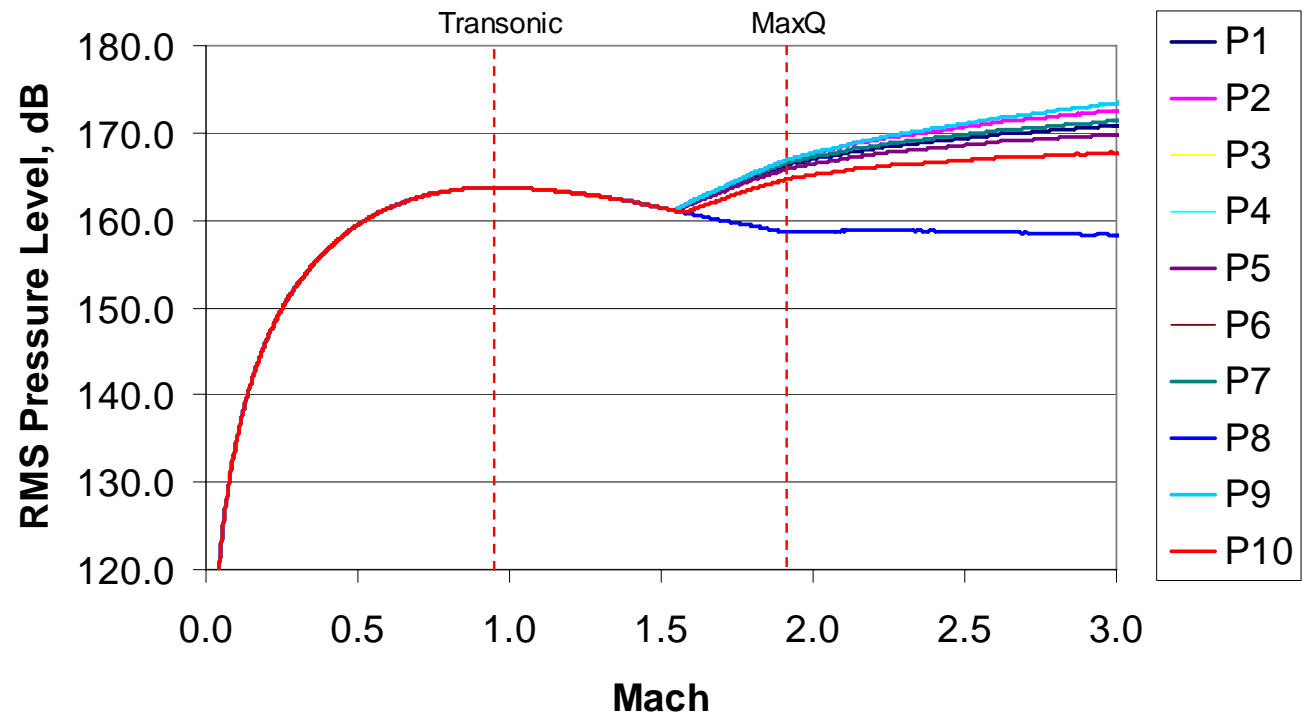

Figure 18. OAFPL near protuberances on Ares I-X during ascent. Reference $=20$ microPascals

Figure 19 and Figure 20 show the FPL one-third-octave-band spectra for selected regions during transonic and MaxQ flight, respectively. It is shown that higher RMS pressure values tend to result in more low-frequency content. However, some exceptions occur, such as the SM and Forward Frustum for transonic flight (Figure 19). This occurs because the Frustum is significantly aft of the SM and therefore in a boundary layer of much higher thickness. Thick boundary layers contain larger eddies, which results in greater low-frequency content.

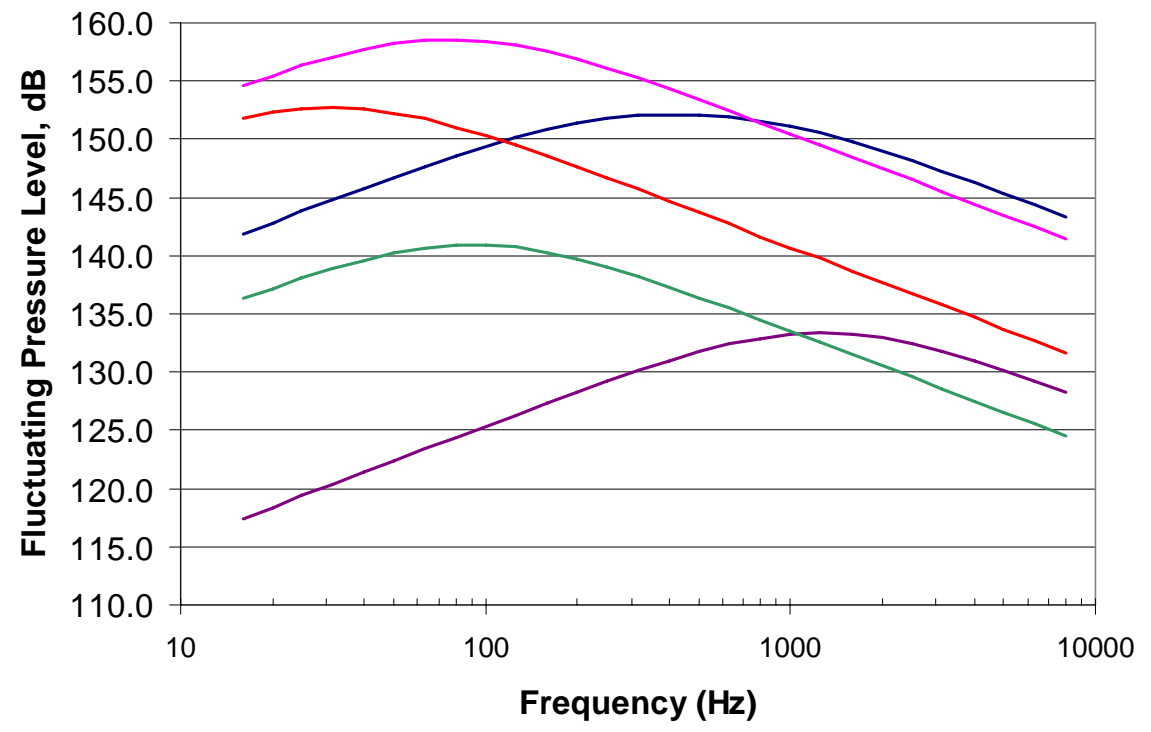

- CM (Comp. Pk w/ Upstream Prot). $165 \mathrm{~dB}-\mathrm{SM}$ (Exp. Pk). $170 \mathrm{~dB}$
- Upper Stage (TBL). $145 \mathrm{~dB}$
- Aft Frustum (Exp. Plateau). $152 \mathrm{~dB}$

Figure 19. FPL one-third-octave-band spectra for selected regions during transonic flight. RMS pressure levels are shown in the legend. 


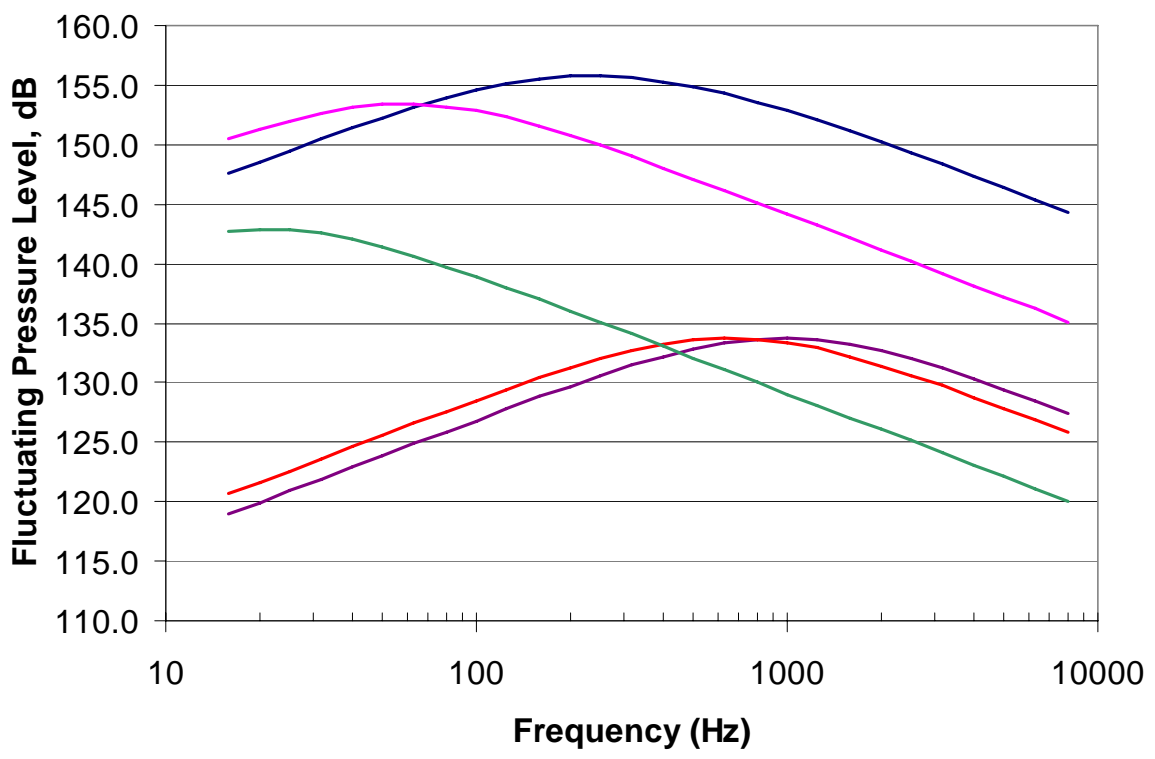

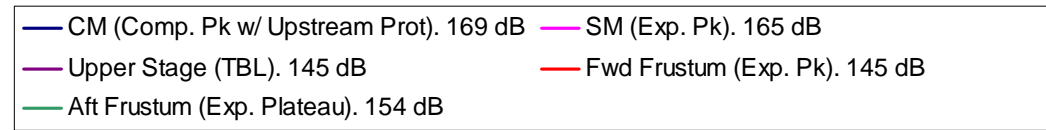

Figure 20. FPL one-third-octave-band spectra for selected regions during MaxQ flight. RMS pressure levels are shown in the legend.

Figure 21 shows the FPL one-third-octave-band spectra for selected protuberances during transonic flight. The effect of the boundary layer thickness on the spectrum is very clear here, as all of the protuberance have the same RMS pressure. The thicker boundary layers encountered near the aft end of the vehicle (P10) result in more lowfrequency content compared to the protuberances at the forward end of the vehicle (P1). Figure 22 is a similar plot for MaxQ flight, and also shows the greater low-frequency content for protuberances near the aft end of the vehicle. However, the effect of the boundary layer thickness is more difficult to see since the slope of the protuberances affects the overall pressure levels. 


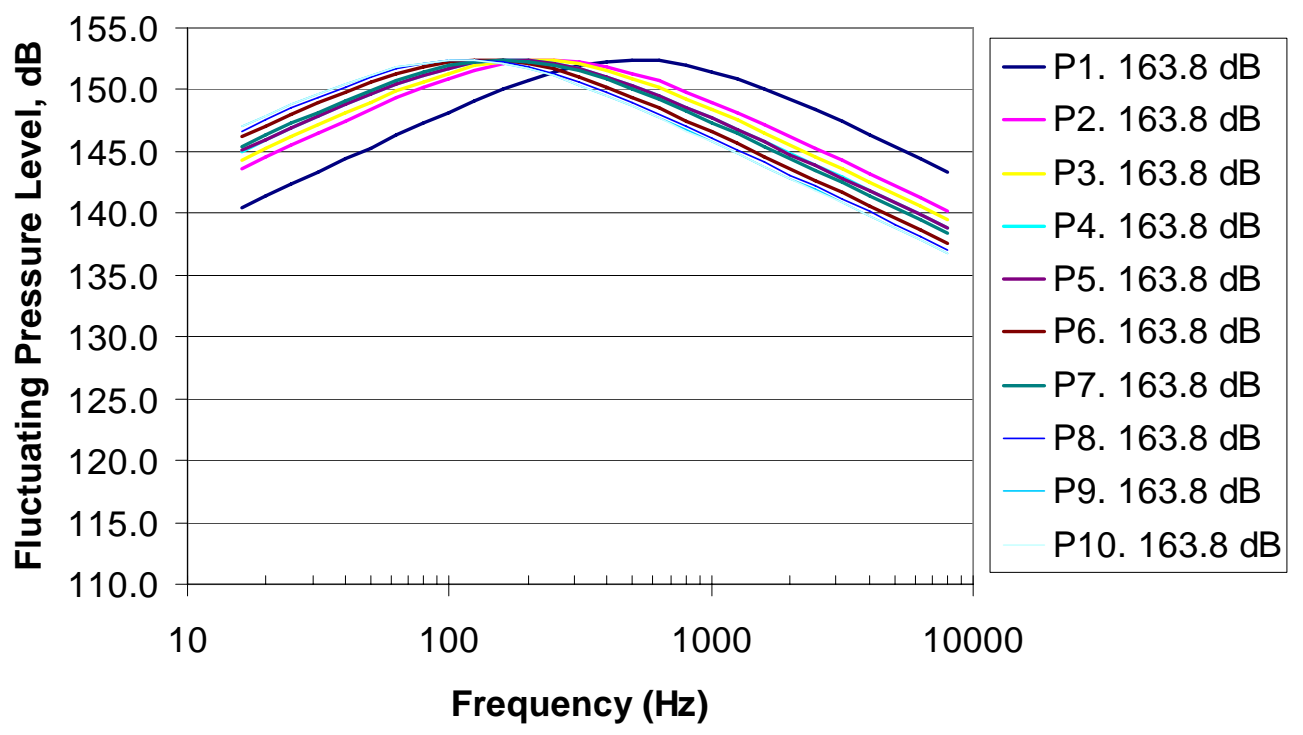

Figure 21. FPL one-third-octave-band spectra for selected protuberances during transonic flight. RMS pressure levels are shown in the legend.

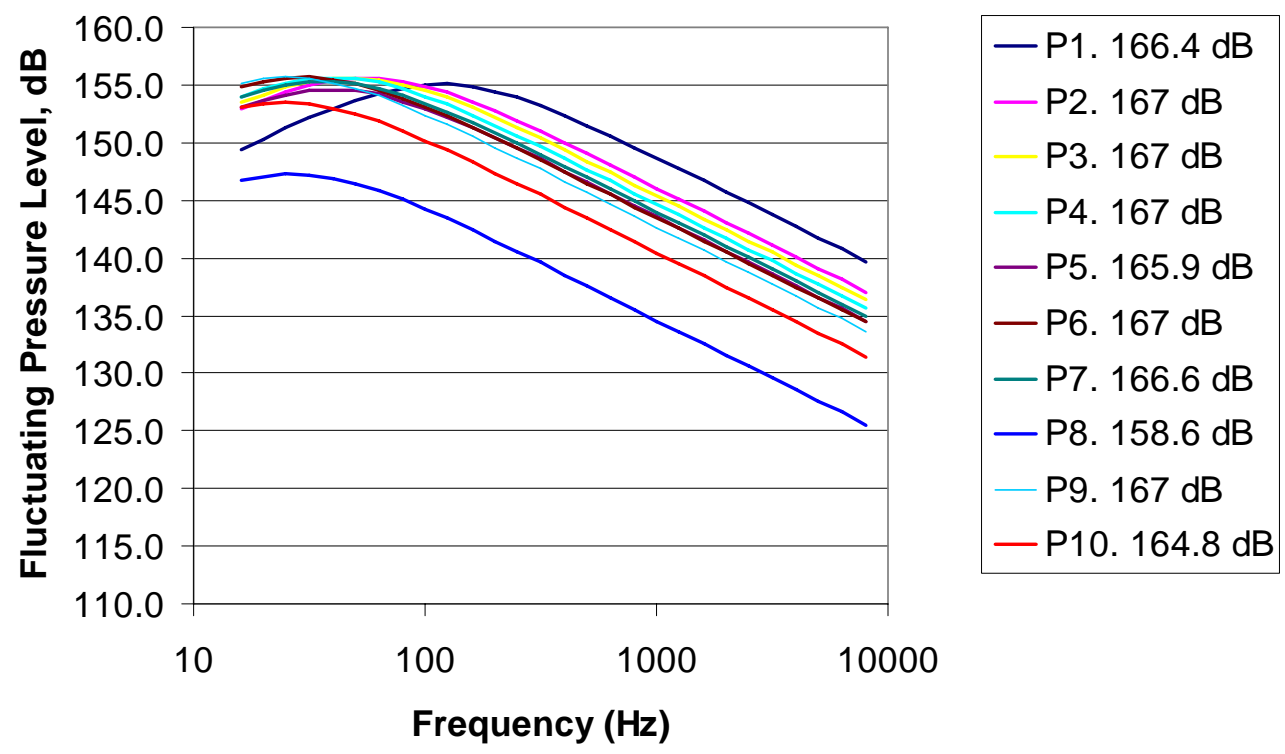

Figure 22. FPL one-third-octave-band spectra for selected protuberances during MaxQ flight. RMS pressure levels are shown in the legend.

\section{Effect of VA-One's TBL Parameters on Predicted Responses}

Although the definition of the external fluctuating pressure environment is important, it is the structural response to these pressures that is of primary interest. The structural response to a fluctuating pressure is strongly dependent on the spatial correlation ${ }^{\dagger+}$, which is unfortunately difficult to define. This section studies the sensitivity of the structural response to parameters that govern the spatial correlation of the fluctuating pressure using the SEA analysis tools available in VA-One ${ }^{\circledR}$.

${ }^{{ }^{+\dagger}}$ The spatial correlation is another term for the real part of the cross-spectral density. 
An SEA model, illustrated in Figure 23, was created for the Roll Control System (RoCS) Shroud, shown as P11 in Figure 9. The protuberance FPL environment was applied as a turbulent boundary layer-type excitation, and the response of the outboard panel was recovered.

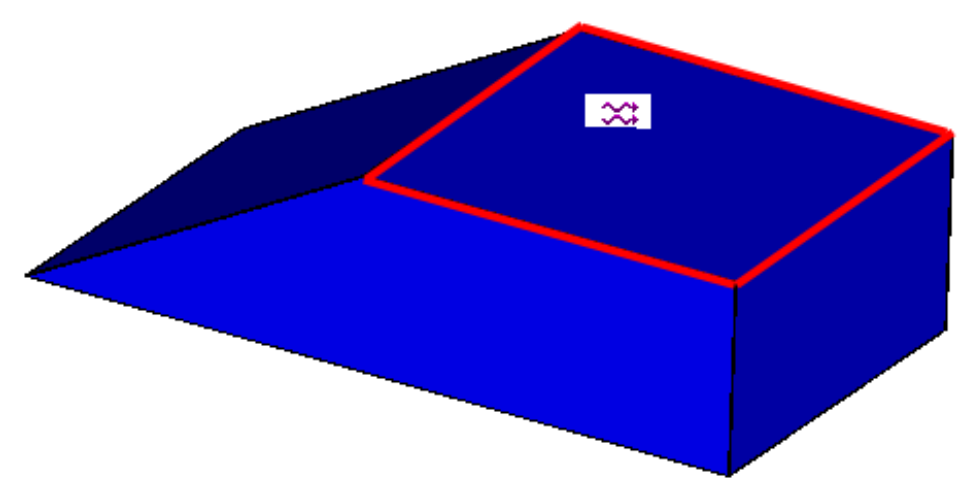

Figure 23. SEA model of RoCS Shroud. Responses were captured for the panel with red boundaries.

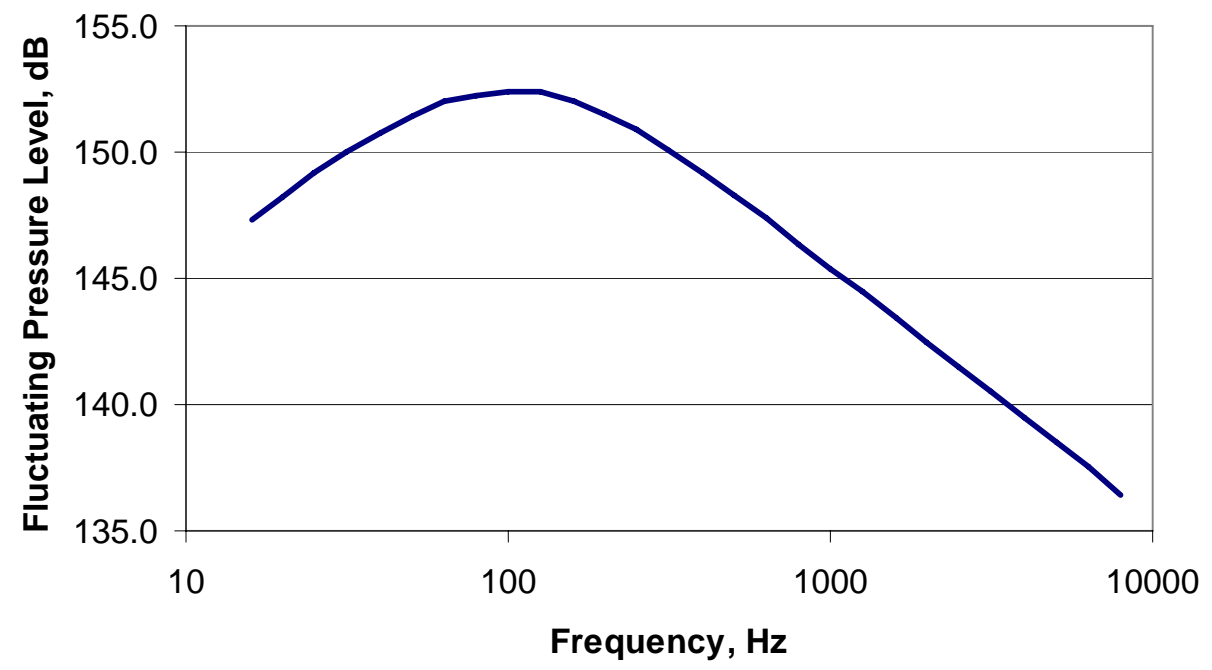

Figure 24. FPL spectrum for RoCS during transonic flight. RMS pressure $=164 \mathrm{~dB}$. Reference $=20$ microPascals

VA-One represents the cross-spectral density as:

$$
R(\xi, \eta, \omega)=\left(e^{-c_{\xi}(\omega) \sqrt{k_{\xi}^{2}(\omega)+k_{\eta}^{2}(\omega)+\left(\frac{1}{3 \delta^{*}}\right)^{2}}|\xi|} \cos \left(k_{\xi}(\omega) \xi\right)\left(e^{-c_{\eta}(\omega) \sqrt{k_{\xi}^{2}(\omega)+k_{\eta}^{2}(\omega)+\left(\frac{1}{3 \delta^{*}}\right)^{2}}|\eta|} \cos \left(k_{\eta}(\omega) \eta\right)\right)\right.
$$

Where:

$$
k_{\xi}=\alpha(\omega) \frac{\omega}{U_{C}}
$$




$$
\begin{gathered}
k_{\eta}=\beta(\omega) \frac{\omega}{U_{C}} \\
U_{C}=\sigma U
\end{gathered}
$$

By default, VA-One sets $\alpha(\omega)=1, \beta(\omega)=0$, and $\sigma=0.7$.

VA-One allows the wavenumbers and spatial correlation decay coefficients to be defined explicitly as a function of frequency. However, this study will use frequency-independent values and study the following parameters:

$\sigma$ - Ratio of the convection and free-stream velocities $(U c / U)$

$x_{o} \quad$ - Distance from the leading edge

$c_{\xi}$ - Spatial correlation decay coefficient in the direction of the flow

$c_{\eta}-\quad$ Spatial correlation decay coefficient perpendicular to the flow

\section{Convection Velocity}

Figure 25a shows that increasing the value of $U_{C}$ leads to a decrease in the wave number of the fluctuating pressure at a given frequency (see also Equation 13). Hydrodynamic coincidence occurs at the frequency at which the structural and fluctuating pressure wavenumbers match, and Figure 25b shows that there is a corresponding peak in the response spectrum at that same frequency.

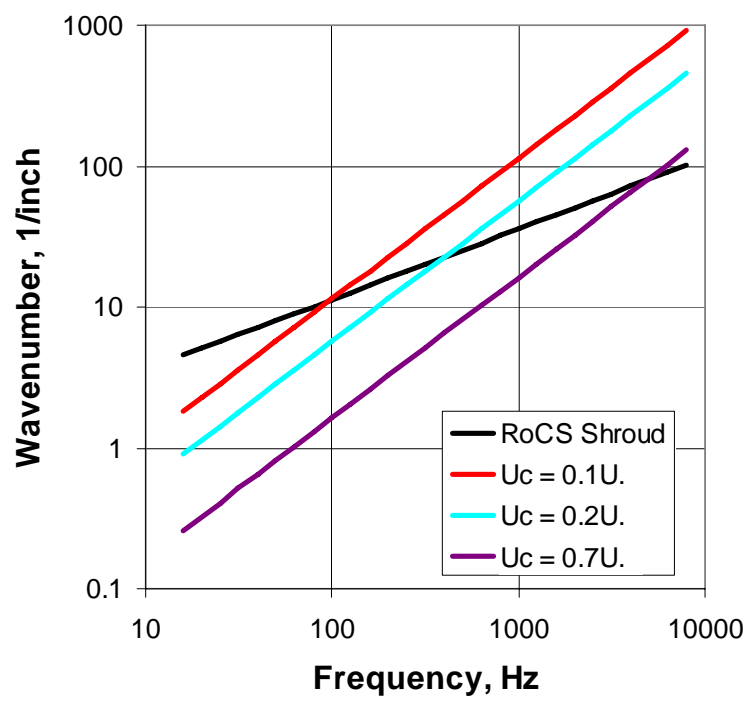

(a) Wavenumber of RoCS Shroud and TBL Excitation

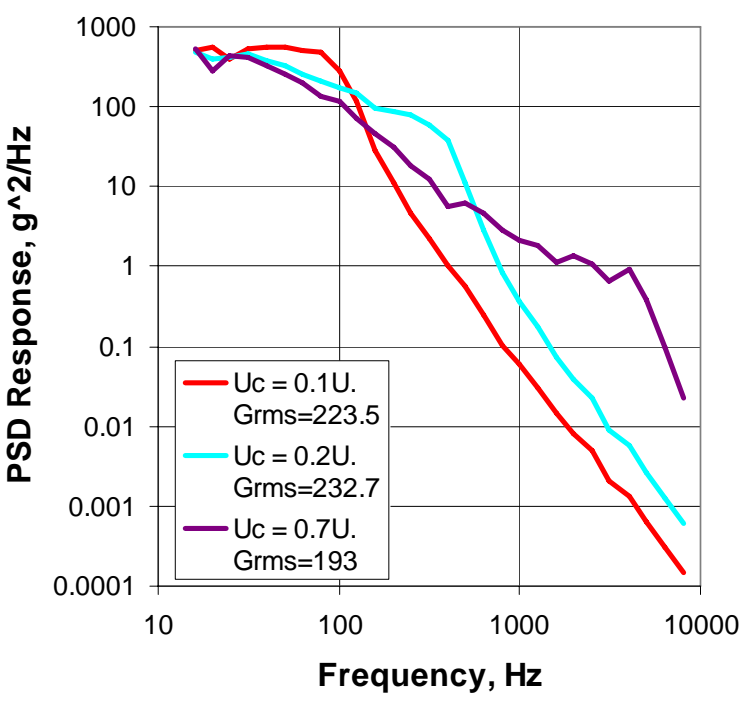

(b) PSD response of RoCS Shroud

Figure 25. A peak in response spectrum occurs at hydrodynamic coincidence frequency

\section{Distance from the Leading Edge}

Figure 26 shows that the low-frequency response of the panel increases as the distance from the leading edge is increased. This occurs because the boundary layer thickness is increasing; resulting in the formation of slower eddies. The figure also shows that the response spectrum asymptotically approaches a final value as the distance from the leading edge continues to increase. 


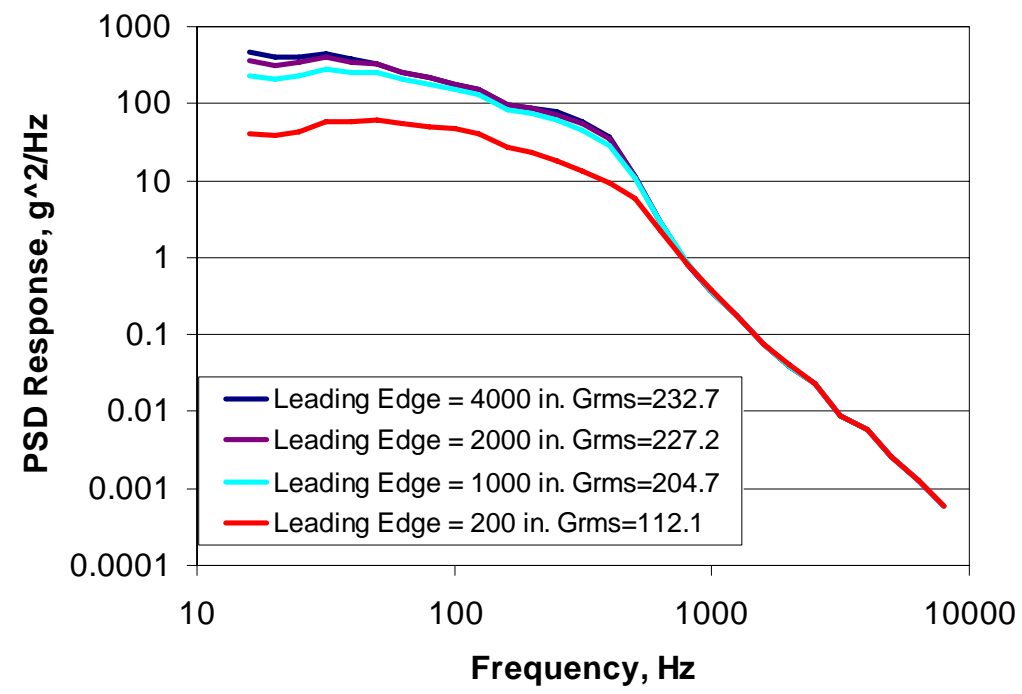

Figure 26. Increasing the distance from the leading edge results in higher low-frequency response. True distance from the vehicle nose is approximately 1700 inches.

\section{Spatial Correlation Decay Coefficient}

Equation 13 shows that as the value of the spatial correlation decay coefficient increases, the effect of the decaying exponential term increases. The excitation therefore becomes more uncorrelated as the coefficient increases, eventually reaching a "rain on the roof" type of excitation once the coefficient becomes sufficiently large. Figure 27 shows that as the excitation becomes less correlated, the peak in the response that is a result of hydrodynamic coincidence begins to decrease, with a corresponding increase in non-coincident response.

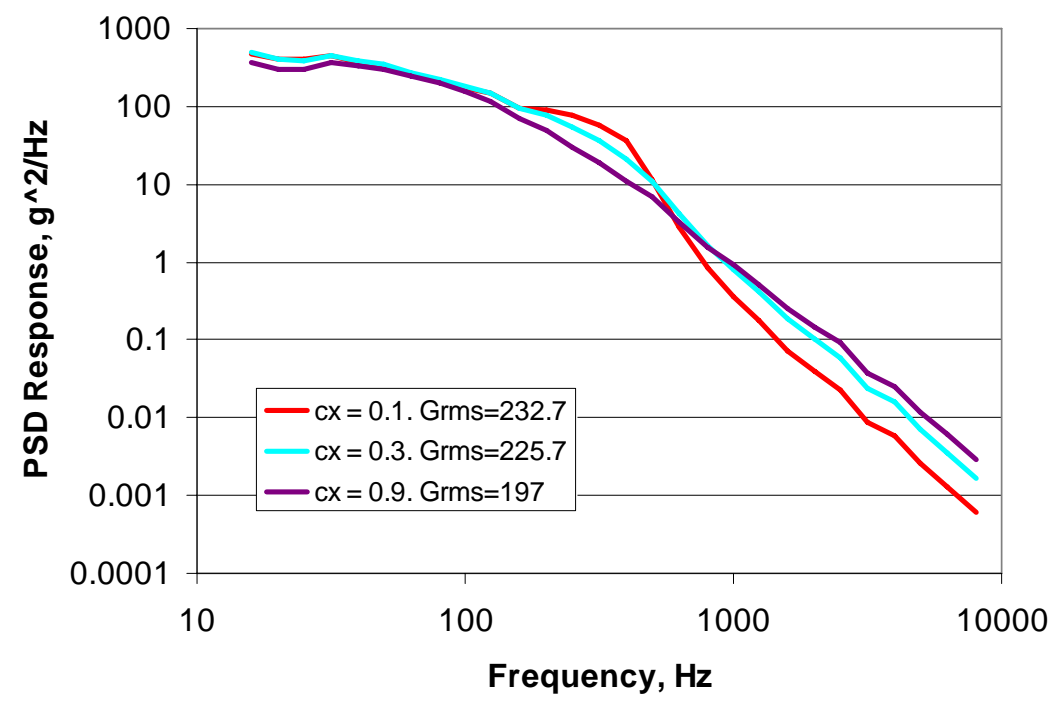

Figure 27. Peaks in response decrease as longitudinal spatial correlation decay coefficient increases. Tangential spatial correlation decay coefficient remains unchanged.

\section{Conclusion}

A description of the aeroacoustic fluctuating pressures model used for the Ares I-X test vehicle has been given, along with corresponding results. This model is based upon the assumption that the flow around a vehicle can be divided into discrete flow zones with independent RMS pressure, autospectra, and cross-spectra. The flow types 
that characterize the zones are attached turbulent boundary layer, compression corners, expansion corners, and protuberances. CFD results predict that the type of flow in certain zones may dramatically change during ascent.

A study was performed on the effect of cross-spectral parameters on the response of the Roll Control System Shroud for Ares I-X. It was found that changing the ratio between the free-stream and convection velocities results in a change in the frequency at which hydrodynamic coincidence occurs. The hydrodynamic coincidence frequency is characterized by large structural responses. Increasing the distance from the leading edge results in an increase in low-frequency response as the boundary layer becomes thicker and producers larger and slower eddies. Finally, the excitation becomes less correlated as the spatial correlation decay coefficient increases. This causes a reduction in the response peak that is a result of hydrodynamic coincidence.

The prediction of fluctuating pressures caused by aerodynamic forces remains very difficult. Currently, it is dependent on the scaling or fitting of empirical wind tunnel and flight data to current vehicles and trajectories. Additionally, the prediction of structural responses to these fluctuating pressures is very difficult, as the responses can change significantly with the spatial correlation. These uncertainties lead to a large amount of conservatism, which results in a significant impact on risk, schedule, and cost. Reducing these uncertainties will require the development of new analytical techniques which must be anchored to experimental results.

\section{Acknowledgments}

This work was funded by NASA under SMAAATAV task NNLO7AC41.

\section{References}

\footnotetext{
${ }^{1}$ Rainey, G., "Progress on the Launch-Vehicle Buffeting Problem,” Journal of Spacecraft and Rockets, Vol. 2, No. 3, 1965, pp. 289-299.

${ }^{2}$ Robertson, J.E., “Prediction of In-flight Fluctuating Pressure Environments Including Protuberance Induced Flow,” Wyle Laboratories Report WR 71-10, March 1971.

${ }^{3}$ Coe, C.F., Chyu, W.J., Dods Jr., J.B., "Pressure Fluctuations Underlying Attached and Separated Supersonic Turbulent Boundary Layers and Shock Waves,” AIAA Paper 73-996, October 1973.

${ }^{4}$ Laganelli, A.L., "Prediction of Pressure Fluctuations on Maneuvering Reentry Weapons,” AFWAL-TR-83-3133, February 1984.

${ }^{5}$ Cockburn, J.A. and Robertson, J.E., "Vibration Response of Spacecraft Shrouds to In-flight Fluctuating Pressures,” Journal of Sound and Vibration. Vol. 33, No. 4, 1974.

${ }^{6}$ Chyu, W.J. and Hanly, R.D., "Power- and Cross-spectra and Space-time Correlations of Surface Fluctuating Pressures at Mach Numbers between 1.6 and 2.5,” AIAA Paper 68-77, January 1968.

${ }^{7}$ Jones, G.W. and Foughner Jr., J.T., "Investigation of Buffet Pressures on Models of Large Manned Launch Vehicle Configurations,” NASA TN D-1633, March 1963.

${ }^{8}$ Shelton, J.D., “Collation of Fluctuating Buffet Pressures for Mercury/Atlas and Apollo/Saturn Configurations,” NASA CR66059.

${ }^{9}$ Speaker, W.V. and Ailman, C.M., "Spectra and Space-time Correlations of the Fluctuating Pressures at a Wall Beneath a Supersonic Turbulent Boundary Layer Perturbed by Steps and Shock Waves,” NASA CR-486, May 1966.

10 Bies, D.A., "A Review of Flight and Wind Tunnel Measurements of Boundary Layer Pressure Fluctuations and Induced Structural Response,” NASA CR-626, 1966.

11 George, B.W., “On Protuberance Noise Environments,” Proceedings of the Acoustical Society of America, Paper XX7, $84^{\text {th }}$ Meeting, Miami Beach, Florida, November 1972.

12 Tran, T. T., Tan, D. K. M., Bogdonoff, S. M., "Surface Pressure Fluctuations in a Three-Dimensional ShockWave/Turbulent Boundary Layer Interaction at Various Shock Strengths” AIAA Paper AIAA 85-1562.

13 Dolling, D. S., Bogdonoff, S. M., “An Experimental Investigation of the Unsteady Behavior at Blunt Fin-Induced Shock Wave Turbulent Boundary Layer Interactions”, AIAA Paper 81-1287, 1981.

14 Nacht, M. L., Turk, R. A., “Origin of High-Intensity Noise in the Area of a Large Protuberance on a Launch Vehicle”, NASA TM X-1261, July 1966.

15 Corcos, G.M., "Resolution of Pressure in Turbulence", Journal of the Acoustical Society of America, Vol. 35, No. 2, February 1963, pp. 192-199.

16 Lowson, M.V., "Prediction of Boundary Layer Fluctuations”, Wyle Laboratories Report WR 67-15, 1967.

17 Blelloch, P., "Effect of Convection Velocity on Launch Vehicle Vibration Response", Proceedings of Noise-Con, Reno, Nevada, October 22-24, 2007.
} 